\title{
Implementing Telemedicine for the Management of Benign Urologic Conditions: A Single Centre Experience in Italy
}

\section{Enrico Checcucci ( $\nabla$ checcu.e@hotmail.it )}

Division of Urology, Dept. of Oncology, School of Medicine, University of Turin, San Luigi Hospital, Orbassano (Turin), Italy

\section{Stefano De Luca}

Division of Urology, Dept. of Oncology, School of Medicine, University of Turin, San Luigi Hospital, Orbassano (Turin), Italy

\section{Paolo Alessio}

Division of Urology, Dept. of Oncology, School of Medicine, University of Turin, San Luigi Hospital, Orbassano (Turin), Italy

\section{Paolo Verri}

Division of Urology, Dept. of Oncology, School of Medicine, University of Turin, San Luigi Hospital, Orbassano (Turin), Italy

\section{Stefano Granato}

Division of Urology, Dept. of Oncology, School of Medicine, University of Turin, San Luigi Hospital, Orbassano (Turin), Italy

\section{Sabrina De Cillis}

Division of Urology, Dept. of Oncology, School of Medicine, University of Turin, San Luigi Hospital, Orbassano (Turin), Italy

\section{Daniele Amparore}

Division of Urology, Dept. of Oncology, School of Medicine, University of Turin, San Luigi Hospital, Orbassano (Turin), Italy

\section{Michele Sica}

Division of Urology, Dept. of Oncology, School of Medicine, University of Turin, San Luigi Hospital, Orbassano (Turin), Italy

\section{Federico Piramide}

Division of Urology, Dept. of Oncology, School of Medicine, University of Turin, San Luigi Hospital, Orbassano (Turin), Italy

\section{Alberto Piana}

Division of Urology, Dept. of Oncology, School of Medicine, University of Turin, San Luigi Hospital, Orbassano (Turin), Italy

\section{Gabriele Volpi}


Division of Urology, Dept. of Oncology, School of Medicine, University of Turin, San Luigi Hospital, Orbassano (Turin), Italy

\section{Matteo Manfredi}

Division of Urology, Dept. of Oncology, School of Medicine, University of Turin, San Luigi Hospital, Orbassano (Turin), Italy

\section{Gabriella Balestra}

Department of Electronics and Telecommunications, Polytechnic University of Turin, Italy

\section{Riccardo Autorino}

Division of Urology, VCU Health, Richmond, VA, USA

\section{Cristian Fiori}

Division of Urology, Dept. of Oncology, School of Medicine, University of Turin, San Luigi Hospital, Orbassano (Turin), Italy

\section{Francesco Porpiglia}

Division of Urology, Dept. of Oncology, School of Medicine, University of Turin, San Luigi Hospital, Orbassano (Turin), Italy

\section{Research Article}

Keywords: telemedicine, Covid-19, BPH, urology, telehealth, phone-counselling

Posted Date: September 29th, 2020

DOI: https://doi.org/10.21203/rs.3.rs-84267/v1

License: (c) (1) This work is licensed under a Creative Commons Attribution 4.0 International License. Read Full License

Version of Record: A version of this preprint was published at World Journal of Urology on January 1st, 2021. See the published version at https://doi.org/10.1007/s00345-020-03536-x. 


\section{Abstract}

Purpose: to assess the use of telemedicine with phone-call visits as practical tool to follow-up with patients affected by urological benign diseases, whose clinic visits had been cancelled during the acute phase of the COVID-19 pandemic.

Methods: patients were contacted via phone-call and a specific questionnaire was administered to evaluate the health status of these patients, and to identify those who needed an "in-person" ambulatory visit due to the worsening of their condition. Secondarily, the patients' perception of a potential shift towards a "telehealth" approach to the management of their condition and to indirectly evaluate their desire to return to "in-person" clinic visits.

Results: 607 were contacted by phone-call. 87.5\% (531/607) of the cases showed stability of the symptoms so no clinic in-person or emergency visits were needed. $81.5 \%(495 / 607)$ of patients were more concerned about the risk of contagion than their urological condition.

The median score for phone visit comprehensibility and ease of communication of exams was $5 / 5$; whilst patients' perception of phone visits' usefulness was scored 4/5. 53\% (322/607) of the interviewees didn't own the basic supports required to be able to perform a real telemedicine consult according to the required standards.

Conclusion: Telemedicine approach limits the number of unnecessary accesses to medical facilities and represent an important tool for the limitation of the risk of transmission of infectious diseases, such as COVID-19. However, infrastructures, health workers and patients should reach out to a computerization process in order to allow a wider diffusion of more advanced forms of telemedicine, such as televisit.

\section{Introduction}

In the era of coronavirus disease 2019 (COVID-19) pandemic, one of the first countries to face this viral infection was Italy, with a first outbreak registered on 21st February 2020 [1]. The Government declared quarantine status and was forced to lock all the non-essential businesses starting from $9^{\text {th }}$ March 2020 to $18^{\text {th }}$ May 2020.

The urological daily practice was overwhelmed [2], with a strong reduction both for surgical [3], emergency [4] and outpatients' activities [5]. In particular, the outpatients' visits in Italy were admitted only for urgencies or emergencies [6].

In this scenario, telehealth and telemedicine offer useful tools that allow to overcoming current challenges and to optimize resources [2]. Patients' feedback on the potential use of telemedicine seems to be overwhelmingly positive. In a recent survey, the $72 \%$ of the interviewees reported to appreciate the use of telemedicine for outpatients' visits during the COVID-19 period; however, this percentage decreased to $49.4 \%$ when considering a post-pandemic scenario [7]. 
The aim of this study was to assess the use of phone call only visits as practical tool to follow-up with patients affected by urological benign diseases, whose clinic visits had been cancelled during the acute phase of the pandemic.

\section{Materials And Methods}

\subsection{Study populations and objectives}

Patients presenting a urological benign disease who had a Urology clinic visit scheduled and cancelled because of the COVID-19 outbreak between $9^{\text {th }}$ March and $18^{\text {th }}$ May 2020 at San Luigi Gonzaga University Hospital (Orbassano, Turin, Italy) were contacted via phone call.

During the call, a specific questionnaire was administered to the patients and data were prospectively collected. First study aim was to evaluate the health status of these patients, to identify those who needed an "in-person" ambulatory visit due to the worsening of their condition. Secondary objective was to evaluate the patients' perception of a potential shift towards a "telehealth" approach to the management of their condition and to indirectly evaluate their desire to return to "in-person" clinic visits.

\subsection{Questionnaire}

A purpose build 17 items questionnaire was administered to the patients during the phone call (supplementary material 1). Demographic variables were collected in terms of age, sex, type of disease (benign prostatic hyperplasia [BPH], urolithiasis, incontinence, infections, andrological issues) and Covid19 status (affected, not affected). Then, results of labs or imaging were also recorded. The first section (4 items) of the questionnaire analyzed patients' health, including type of disease, its stability, and onset of a new problem/issue. Patients were recommended to postpone the follow-up or to plan an in-person visit depending on the findings at the phone call. The second section evaluated patients' appreciation for the phone counselling by using a five-point Likert scale (1: extremely disappointed; 5 : absolutely appreciated). Last, patients' attitude for a more advanced telehealth visit (including video consultation with the possibility to transmit radiological or laboratory exams) was assessed.

\subsection{Statistical analysis}

Descriptive statistics included frequencies and proportions for continuous and categorical variables, respectively.

\section{Results}

\subsection{Demographics findings}

Six hundred and seven patients with a benign urologic disease were contacted by telephone by the medical staff of the Department of Urology. Median age of this population was 74 years (range 44-89 
years), and most patients were male (76.9\%). Most common conditions were: $\mathrm{BPH}(\mathrm{n}=490 ; 80.7 \%)$ and urolithiasis $(n=69 ; 11.4 \%)$ (Table 1$)$.

Table 1: Demographics variables (BPH: benign prostatic hyperplasia)

\begin{tabular}{|l|c|}
\hline Demographics variables & 607 patients \\
\hline Age, years; median (IQR) & $74(44-89)$ \\
\hline Male; $\mathrm{N}^{\circ}(\%)$ & $467(76.9)$ \\
\hline Disease, $\mathrm{N}^{\circ}(\%)$ & $490(80.7)$ \\
- BPH & $69(11.4)$ \\
- Urolithiasis & $48(7.9)$ \\
- Andrology and others & \\
\hline
\end{tabular}

\subsection{Clinical findings}

$12.5 \%(76 / 607)$ of patients showed a worsening of the urological condition or an onset of new symptoms; thus, a in person consult was scheduled in the following 15 days. On the other hand, $87.5 \%$ $(531 / 607)$ of the cases showed stability of the symptoms at the phone interview, so no clinic or emergency visits were needed (Table 2).

Table 2: Clinical outcomes of phone-counselling (FU: Follow-up; ED: emergency department). *According to Italian Ministry of Health disposition "priority B" means that the visit should be execute within 2 weeks

\begin{tabular}{|l|c|}
\hline Clinical outcomes & \\
\hline Health status, $\mathrm{N}^{\circ}(\%)$ & $531(87.5)$ \\
- Stable & $26(4.2)$ \\
: Worsening & \\
\hline Exam presented, $\mathrm{N}^{\circ}(\%)$ & $303(49.9)$ \\
- First level & $291(47.9)$ \\
- Secondary level & $531(87.5)$ \\
\hline $\begin{array}{l}\text { Phone-counselling outcomes, } \mathrm{N}^{\circ}(\%) \\
\text { - Planned FU visit }\end{array}$ & $\begin{array}{c}(12.5) \\
\text { - Indicated clinical visit with priority B* } \\
\text { - Indicated access to ED }\end{array}$ \\
\hline
\end{tabular}

\subsection{Telemedicine evaluation}

$81.5 \%$ (495/607) of patients were more concerned about the risk of contagion than their urological condition (Figure 1). Furthermore, 66\% (401/607) stated that they would have postponed an in-person consult, if this had not been canceled, because of the fear of contracting COVID-19.

Concerning the evaluation of patients' opinion on the use of telemedicine, the median score for phone visit comprehensibility and ease of communication of exams was $5 / 5$. The median score for the patients' 
perception of phone visits' usefulness was $4 / 5$ (Table 3$)$. About half $(46 \% ; 279 / 607)$ of the patients approved being followed up with a telemedicine approach, even after the COVID emergency (Figure 2).

Table 3: Telemedicine evaluation (*these items were assessed by using a 5-point Likert scale, see captions on the questionnaire attached).

\begin{tabular}{|c|c|}
\hline Telemedicine evaluation & \\
\hline Q.7 Was the telemedicine consult comprehensible? [Median (IQR)]* & $\begin{array}{c}5(4- \\
5)\end{array}$ \\
\hline $\begin{array}{l}\text { Q.8 How difficult was it to explain your physical conditions and symptoms? } \\
\text { [Median (IQR) }]^{*}\end{array}$ & $\begin{array}{c}4(3- \\
4)\end{array}$ \\
\hline Q.9 How easy was it to communicate the results of the exams? [Median (IQR)]* & $\begin{array}{l}4(4- \\
5)\end{array}$ \\
\hline $\begin{array}{l}\text { Q.10 How "depersonalized "do you perceive the doctor-patient relationship using } \\
\text { telemedicine for health consults? [Median (IQR)]* }\end{array}$ & $\begin{array}{l}4(3- \\
5)\end{array}$ \\
\hline Q.11 Was the telemedicine consult useful? [Median (IQR)]* & $\begin{array}{l}4(4- \\
5)\end{array}$ \\
\hline Q.12 Was the telemedicine consult easy to carry out? [Median (IQR)]* & $\begin{array}{c}5(4- \\
5)\end{array}$ \\
\hline $\begin{array}{l}\text { Q.13 How much do you appreciate this phone-counselling approach? [Median } \\
\text { (IQR)]* }\end{array}$ & $\begin{array}{c}5(4- \\
5)\end{array}$ \\
\hline $\begin{array}{l}\text { Q.14 Is the telemedicine visit more comfortable to carry out, compared to the } \\
\text { classic consultation? } \mathrm{N}^{\circ}(\%)\end{array}$ & \\
\hline $\begin{array}{l}\text { - Yes } \\
\text { - No }\end{array}$ & $\begin{array}{l}394 \\
213\end{array}$ \\
\hline Q.15 Do you own any IT support? $\mathrm{N}^{\circ}(\%)$ & \\
\hline $\begin{array}{l}\text { - No } \\
\text { - } \mathrm{PC} \\
\text { - Tablet } \\
\text { smartphone }\end{array}$ & $\begin{array}{c}(1.9) \\
182 \\
(29.6) \\
175 \\
(28.8) \\
578 \\
(95.2)\end{array}$ \\
\hline $\begin{array}{l}\text { Q.16 Would you have the possibility to carry out this visit with the help of an IT } \\
\text { support? } N(\%)\end{array}$ & \\
\hline $\begin{array}{l}\text { - Yes } \\
\text { - No }\end{array}$ & $\begin{array}{c}(47.0) \\
322 \\
(53.0)\end{array}$ \\
\hline $\begin{array}{l}\text { Q.17 Having experienced the COVID crisis, would you be willing to be followed- } \\
\text { up using telemedicine even in the post-COVID period? }\end{array}$ & \\
\hline $\begin{array}{l}\text { - Yes } \\
\text { - No }\end{array}$ & $\begin{array}{c}194 \\
(32.0) \\
413 \\
(68.0) \\
\end{array}$ \\
\hline
\end{tabular}

Lastly, 53\% (322/607) of the interviewees didn't own the basic supports required to be able to perform a real telemedicine consult (computer, tablet, smartphone, internet connection). Furthermore, $68 \%$ $(413 / 607)$ stated that even if they had had the chance, they would not have been able to carry out an online visit according to the required standards. 


\section{Discussion}

During the hardest phase of the pandemic, in each single country, the majority of the population encountered restrictions, affecting their daily routines. In particular, the avoidance of physical contact was stressed following the \#stayathome trend. Focusing on health services, the follow-up ambulatory visits for benign pathology were postponed or cancelled, also in Italy [9].

In this context, to cope with the COVID-19 pandemic, the use of telemedicine for patients' health management steps into the limelight, even in urology. Telemedicine represents a peculiar instrument which, when used for selected populations of patients, can be compared to traditional counseling, as stated by Novara et al [2]. Thanks to this instrument, physicians can offer effective and high-quality clinical consultations.

In order to fill the blank of official guidelines concerning the correct execution of a telemedicine counseling, Socarrás et al [8] outlined its main principles and characteristics, highlighting some crucial aspects such the maintenance of professionalism, privacy, confidentiality whilst reaching satisfying levels of data transmission and comprehension.

Our study reported the data of more than 600 phone counselling for urological benign pathology: notwithstanding the simple call may seem an obsolete approach for telemedicine and may even seem inadequate for clinical visits, it perfectly matches the recommendations of the European Association of Urology [8]. In fact, the phone call, performed by using hospital phones, can be considered the first and easiest approach for telemedicine, as reported in previously published experiences, for the management of prostate cancer [11], hematuria [12], stones $[13,14]$, urinary incontinence $[15,16]$ and urinary tract infections [17].

Focusing on clinical findings of our study, it is worth noticing that all patients presented a benign disease (mostly BPH), and only in $8 \%$ of the cases a worsening of the clinical condition was recorded, and in $12.5 \%$ of the cases a traditional visit within two weeks was recommended. No patients required to go to ER for an urgent visit. On the contrary, most of the interviewers reported stability of the symptoms. Thus, phone counselling made by medical staff allowed to perform a triage to discriminate the patient's clinical condition with a subsequent optimization of the hospital resources, allowing the access to patients with a real need.

Another important finding was that more than $80 \%$ of the patients were more worried about the viral infections than their urological diseases. Moreover, $66 \%$ of patients stated their intention to postpone their visit due to COVID-19 emergency. These percentage was very high probably because the patients were affected by benign diseases, with a clinical stability in $85 \%$ of the cases. On the contrary, in our series for oncological disease, only $20 \%$ of the patients would postpone their treatment [18]; whilst in Rodler et al experience, $56 \%$ of the patients were more anxious about their malignant disease than about COVID-19 [19]. 
However, the most interesting findings of our study concerns the evaluation of patients' perception on telemedicine approach. In $88 \%$ of the cases the appreciation for this telematic approach was rated $5 / 5$ ("absolutely appreciated" by using the five-point Likert scale). These findings are in line with our previous experiences evaluating the perceptions of patients waiting for urological procedures during COVID-19 lockdown at our center, which reported a high appreciation for telemedicine in $72 \%$ of the cases [7]. As expected, this value decreased to $46 \%$ when we evaluated its potential application in post-pandemic era, probably due to the scarce knowledge about this kind of approach by the patients.

Notwithstanding these encouraging findings, our analysis showed that the patients are not ready for a more modern telemedicine approach, such as tele-visiting. In fact, the $53 \%$ did not have an adequate support (PC, tablet, smartphone); moreover $68 \%$ of patients declared that, even if available, they would not have the instruments to perform an online visit. A 2019 survey reported by Cacciamani et al investigating the popularity of telemedicine in the US, showed that lack of access (34.6\%) and poor awareness (39.7\%) of telehealth options represent the main limitations to the spreading of this instrument [20], with an estimated $10 \%$ of Americans to have experienced a telehealth visit. In fact, the most popular tools for virtual communication resulted to be, in decreasing order of preference, phone call (76.9\%), e-mail (56.7\%), patient-reported outcome applications (22.0\%), and video call (14.3\%), as reported by Rodler et al [19].

It is important to note that telemedicine represents a new area for both physicians and patients. The latter, particularly when elderly, may be unable to effectively use electronic devices, making an electronic consultation hard to perform. As suggested by Sosnowski et al [21], the urologist can play an essential role in offering the patient the best option, choosing the most appropriate communication tool, and considering all the variables and the patient's needs and preferences. The role of caregivers should also be maximized and integrated inside this context, since they can be helpful in the communication process. Moreover, in this setting, patients should be able to get in touch with the physician as soon as a new problem arise, in order to promptly schedule a follow-up visit.

The main limitation of the present study should be mentioned. Phone-counselling allowed to perform a triage visit without the chance to adequately evaluate blood tests or radiological exams, and no change in pharmacological therapy was suggested, intrinsically limiting the in-depth analysis of clinical investigation of this kind of approach.

However, taking together all of these findings, one can argue that even if telemedicine is highly appreciated both by doctors and patients, current health care infrastructures remain inadequate and low access to computers of the patients represent the main challenges for a real transition to telemedicine in current daily clinical practice. Therefore, health practitioners should become increasingly familiar with telemedicine and, at the same time, national and regional initiatives to improve patients' digital "literacy" should be implemented.

\section{Conclusions}


Implementing telemedicine tools for the management of urology patients with benign conditions in the current COVID-19 era carries several potential advantages and it is well perceived by most doctors and patients. However, efforts should be made to improve current infrastructures and access to computer technology to allow a wider diffusion of telemedicine and a real transition to more advanced forms of telehealth.

\section{Declarations}

\section{AUTHOR'S CONTRIBUTION}

E Checcucci: Manuscript writing, data analysis

S De Luca: Project development, supervision of manuscript writing

P Alessio: Data collection

P Verri: Data collection, manuscript editing

S Granato: Data collection

S De Cillis: Data collection, manuscript writing

D Amparore: manuscript writing

M Sica: Data collection

F Piramide: Data collection

A Piana: Data collection

G Volpi: Data collection

M Manfredi: Supervision of manuscript writing

G Balestra: Supervision of manuscript writing

R Autorino: Supervision of manuscript writing

C Fiori: Project development, supervision of manuscript writing

F Porpiglia: Project development, supervision of manuscript writing

CONFLICT OF INTEREST

All Authors have nothing to disclose. 
The author(s) did not receive specific funding for this work.

\section{CONSENT TO PARTICIPATE}

Oral informed consent was obtained from all individual participants included in the study.

\section{CONSENT TO PUBLISH}

The authors affirm that human research participants provided oral informed consent for publication.

\section{References}

1. Remuzzi A, Remuzzi G. COVID-19 and Italy: what next? Lancet. 2020 Apr 11;395(10231):1225-1228. doi: 10.1016/S0140-6736(20)30627-9. Epub 2020 Mar 13. Review. PubMed PMID: 32178769; PubMed Central PMCID: PMC7102589.

2. Amparore D, Campi R, Checcucci E, Sessa F, Pecoraro A, Minervini A, Fiori C, Ficarra V, Novara G, Serni S, Porpiglia F. Forecasting the Future of Urology Practice: A Comprehensive Review of the Recommendations by International and European Associations on Priority Procedures During the COVID-19 Pandemic. Eur Urol Focus. 2020 May 31. pii: S2405-4569(20)30142-5. doi: 10.1016/j.euf.2020.05.007. [Epub ahead of print] Review. PubMed PMID: 32553544; PubMed central PMCID: PMC7261455.

3. Campi R, Amparore D, Capitanio U, Checcucci E, Salonia A, Fiori C, Minervini A, Briganti A, Carini M, Montorsi F, Serni S, Porpiglia F. Assessing the Burden of Nondeferrable Major Uro-oncologic Surgery to Guide Prioritisation Strategies during the COVID-19 Pandemic: Insights from Three Italian Highvolume Referral centres. Eur Urol. 2020 Jul;78(1):11-15. doi: 10.1016/j.eururo.2020.03.054. Epub 2020 Apr 11. Review. PubMed PMID: 32307215; PubMed Central PMCID: PMC7151319.

4. Novara G, Bartoletti R, Crestani A, De Nunzio C, Durante J, Gregori A, Liguori G, Pavan N, Trombetta C, Simonato A, Tubaro A, Ficarra V, Porpiglia F; members of the Research Urology Network (RUN) (see appendix). Impact of the COVID-19 pandemic on urological practice in emergency departments in Italy. BJU Int. 2020 May 14. doi: 10.1111/bju.15107. [Epub ahead of print] PubMed PMID: 32407585; PubMed Central PMCID: PMC7273082.

5. Simonato A, Giannarini G, Abrate A, Bartoletti R, Crestani A, De Nunzio C,Gregori A, Liguori G, Novara G, Pavan N, Trombetta C, Tubaro A, Porpiglia F, Ficarra V; Research Urology Network (RUN). Clinical pathways for urology patients during the COVID-19 pandemic. Minerva Urol Nefrol. 2020 Jun;72(3):376-383. doi: 10.23736/S0393-2249.20.03861-8. Epub 2020 Mar 30. PubMed PMID: 32225135.

6. Ficarra V, Novara G, Abrate A, Bartoletti R, Crestani A, De Nunzio C,Giannarini G, Gregori A, Liguori G, Mirone V, Pavan N, Scarpa RM, Simonato A, Trombetta C, Tubaro A, Porpiglia F; Research Urology Network (RUN). Urology practice during the COVID-19 pandemic. Minerva Urol Nefrol. 2020Jun;72(3):369-375. doi: 10.23736/S0393-2249.20.03846-1. Epub 2020 Mar 23. PubMed PMID: 32202401. 
7. Amparore D, Campi R, Checcucci E, Piana A, Sica M, Grosso A, Presutti M, Barzaghi P, Minervini A, Serni S, Fiori C, Porpiglia F; Patients'perspective on the use of telemedicine for outpatients urological visits: learning from the COVID-19 outbreak. Actas Urol Esp. 2020 Jul; https://doi.org/10.1016/j.acuro.2020.06.008 [Epub ahead of print]

8. Rodriguez Socarrás M, Loeb S, Teoh JY, Ribal MJ, Bloemberg J, Catto J, N'Dow J, Van Poppel H, Gómez Rivas J. Telemedicine and Smart Working: Recommendations of the European Association of Urology. Eur Urol. 2020 Jul pii:S0302-2838(20)30460-7. doi: 10.1016/j.eururo.2020.06.031. [Epub ahead of print]Review. PubMed PMID: 32654801; PubMed Central PMCID: PMC7347487.

9. DECRETO-LEGGE 17 marzo 2020, n. 18. Misure di potenziamento del Servizio sanitario nazionale e di sostegno economico per famiglie, lavoratori e imprese connesse all'emergenza epidemiologica da COVID-19. (20G00034) (GU Serie Generale n.70 del 17-03-2020). Available at https://www.gazzettaufficiale.it/eli/id/2020/03/17/20G00034/sg

10. Novara G, Checcucci E, Crestani A, Abrate A, Esperto F, Pavan N, De Nunzio C, Galfano A, Giannarini G, Gregori A, Liguori G, Bartoletti R, Porpiglia F, Scarpa RM, Simonato A, Trombetta C, Tubaro A, Ficarra V; Research Urology Network (RUN). Telehealth in Urology: A Systematic Review of the Literature. How Much Can Telemedicine Be Useful During and After the COVID-19 Pandemic? Eur Urol. 2020 Jun pii: S0302-2838(20)30454-1. doi: 10.1016/j.eururo.2020.06.025. [Epub ahead of print] Review. PubMed PMID: 32616405; PubMed Central PMCID: PMC7301090.

11. Parsons JK, Newman V, Mohler JL, Pierce JP, Paskett E, Marshall J; Cancer and Leukemia Group B. The Men's Eating and Living (MEAL) study: a Cancer and Leukemia Group B pilot trial of dietary intervention for the treatment of prostate cancer. Urology. 2008 Sep;72(3):633-7. doi: 10.1016/j.urology.2007.11.050. Epub 2008 Feb 15. PubMed PMID: 18280560.

12. Safir IJ, Gabale S, David SA, Huang JH, Gerhard RS, Pearl J, Lorentz CA, Baumgardner J, Filson CP, Issa MM. Implementation of a Tele-urology Program for Outpatient Hematuria Referrals: Initial Results and Patient Satisfaction. Urology. 2016 Nov;97:33-39. doi: 10.1016/j.urology.2016.04.066. Epub 2016 Jul 19. PubMed PMID: 27450940.13.

13. Connor MJ, Miah S, Edison MA, Brittain J, Smith MK, Hanna M, El-Husseiny T,Dasgupta R. Clinical, fiscal and environmental benefits of a specialist-led virtual ureteric colic clinic: a prospective study. BJU Int. 2019 Dec;124(6):1034-1039. doi: 10.1111/bju.14847. Epub 2019 Jul 2. PubMed PMID:31206221.

14. Nevo A, Stern KL, Moore JP, Humphreys MR, Tyson MD, Keddis MT. The impact of phone counseling on urinary stone prevention. World J Urol. 2020 Jun 25. doi: 10.1007/s00345-020-03320-x. [Epub ahead of print] PubMed PMID: 32588206.

15. Jones G, Brennan V, Jacques R, Wood H, Dixon S, Radley S. Evaluating the impact of a 'virtual clinic' on patient experience, personal and provider costs of care in urinary incontinence: A randomised controlled trial. PLoS One. 2018 Jan 18;13(1):e0189174. doi: 10.1371/journal.pone.0189174. eCollection 2018. PubMed PMID: 29346378; PubMed Central PMCID: PMC5773012. 
16. Balzarro M, Rubilotta E, Trabacchin N, Mancini V, Costantini E, Artibani W, Antonelli A. A Prospective Comparative Study of the Feasibility and Reliability of Telephone Follow-Up in Female Urology: The Patient Home Office Novel Evaluation (PHONE) Study. Urology. 2020 Feb;136:82-87. doi:10.1016/j.urology.2019.10.021. Epub 2019 Nov 11. PubMed PMID: 31726182.

17. Schauberger CW, Merkitch KW, Prell AM. Acute cystitis in women: experience with a telephone-based algorithm. WMJ. 2007 Sep;106(6):326-9. PubMed PMID:17970014.

18. Campi R, Amparore D, Capitanio U, Checcucci E, Salonia A, Fiori C, Minervini A, Briganti A, Carini M, Montorsi F, Serni S, Porpiglia F. Reply to Vincenzo Ficarra, Giuseppe Mucciardi, and Gianluca Giannarini's Letter to the Editor re: Riccardo Campi, Daniele Amparore, Umberto Capitanio, et al. Assessing the Burden of Nondeferrable Major Uro-oncologic Surgery to Guide Prioritisation Strategies During the COVID-19 Pandemic: Insights from Three Italian High-volume Referral Centres. Eur Urol. In Press. https://doi-org.bibliopass.unito.it/10.1016/j.eururo.2020.03.054. Eur Urol. 2020 May 22. pii: S0302-2838(20)30357-2. doi: 00.1016/j.eururo.2020.05.017.[Epub ahead of print] PubMed PMID: 32475746; PubMed Central PMCID: PMC7242972.

19. Rodler S, Apfelbeck M, Schulz GB, Ivanova T, Buchner A, Staehler M, Heinemann V, Stief C, Casuscelli J. Telehealth in Uro-oncology Beyond the Pandemic: Toll or Lifesaver? Eur Urol Focus. 2020 Jun 10. pii: S2405-4569(20)30145-0. doi: 10.1016/j.euf.2020.05.010. [Epub ahead of print] PubMed PMID: 32534969; PubMed Central PMCID: PMC7286644.

20. Cacciamani GE, Shah M, Yip W, Abreu A, Park D, Fuchs G. Impact of Covid-19 on the urology service in United States: perspectives and strategies to face a Pandemic. Int Braz J Urol. 2020 Jul;46(suppl.1):207-214. doi:10.1590/S1677-5538.IBJU.2020.S126. PubMed PMID: 32618466.

21. Sosnowski R, Kamecki H, Joniau S, Walz J, Klaassen Z, Palou J. Introduction of Telemedicine During the COVID-19 Pandemic: A Challenge for Now, an Opportunity for the Future. Eur Urol. 2020 Jul 14. pii: S0302-2838(20)30539-X. doi: 10.1016/j.eururo.2020.07.007. [Epub ahead of print] PubMed PMID: 32703638; PubMed Central PMCID: PMC7359784.

\section{Figures}




\section{Perception of Covid-19 dangerousness}

Overall

Fig. 1

\section{Figure 1}

Graphical representation of the patient's anxious for their urological conditions or Covid-19

\section{Telemedicine evaluation}

How much do you appreciate this phone-counselling approach?

Was the telemedicine consult easy to carry out?

Was the telemedicine consult useful?

How "depersonalized "do you perceive the doctor-patient relationship using telemedicine for health consults?

How easy was it to communicate the results of the exams?

How difficult was it to explain your physical conditions and symptoms?

Was the telemedicine consult comprehensible

Fig. 2
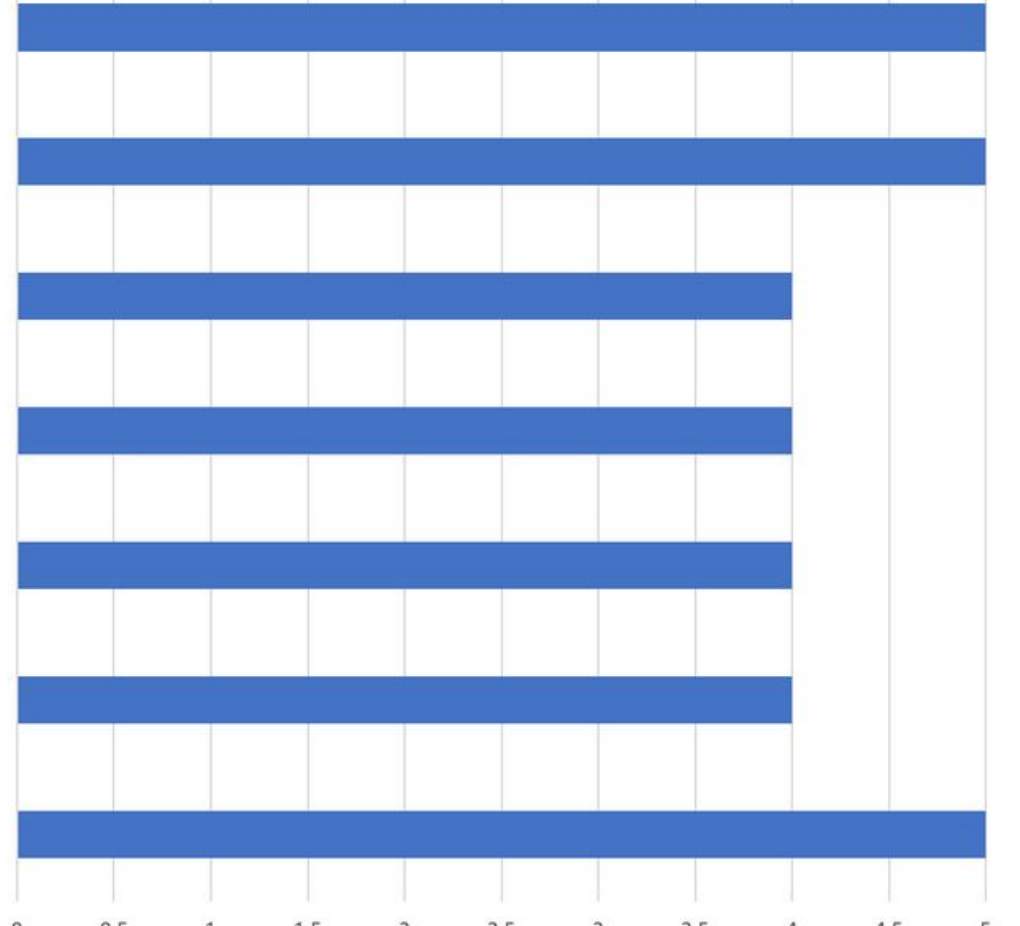

\section{Figure 2}


Telemedicine and the phone-counselling approach performed were tested by using a five-point Likert scale evaluating the patients' perception.

\section{Supplementary Files}

This is a list of supplementary files associated with this preprint. Click to download.

- Supplementarymaterial1.docx 